\title{
Entrevista
}

\section{Language Acquisition, PROcessing and Syntax (LAPROS)}

\author{
Thiago Motta ${ }^{1}$
}

Universidade Estadual de Campinas

\section{Entrevista concedida aos professores Kátia Abreu e Eduardo Kenedy}

Soletras: Quando o seu LAB foi fundado? Qual foi sua experiência em LABs de Psicolinguística anterior à fundação do LAB que coordena?

O LAPROS (Language Acquisition, PROcessing and Syntax, UNICAMP) acabou de completar um ano, no dia 5 de maio. Antes do LAPROS, tive experiência no LAPEX (UFRJ coordenado pelo Prof. Marcus Maia) e nos laboratórios de neurociência ACESIN (UFRJ, de Aniela Improta França) e no UNICOG (NeuroSpin Center, na França, coordenado por Stanislas Dehaene).

Soletras: Quais os principais temas de pesquisa que seu LAB vem contemplando ao longo dos anos?

O LAPROS nasceu do esforço conjunto de três professores da UNICAMP, cada um com sua própria frente de pesquisa: Ruth Lopes, Pablo Faria e Thiago Motta Sampaio. Ruth Lopes é conhecida na área de aquisição de linguagem, tendo organizado o SEAL (Sala Experimental em Aquisição de Linguagem), que hoje faz parte do LAPROS. Pablo Faria é professor de aquisição de linguagem e trabalha com Processamento de Linguagem Natural (Linguística Computacional). A pesquisa de Pablo consiste na elaboração de modelos algorítmicos que simulam a aquisição e o processamento de linguagem. E eu já trabalho com processamento de linguagem em adultos, fechando as três grandes frentes de estudo do laboratório.

1 Coordenador da equipe de Processamento de Sentenças e co-fundador do Language Acquisition, Processing and Syntax Lab (LAPROS). Professor de Psicolinguística e Processos Cognitivos na Unicamp. thiagomotta@iel.unicamp.br 


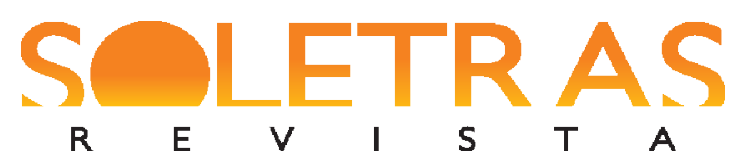

N. 33 ï 2017.1 ï THIAGO MOTA

Soletras: Quais as principais técnicas experimentais que vêm sendo empregadas nas pesquisas de seu Lab nos últimos anos?

Em aquisição: basicamente testes de olhar preferencial, além de diferentes métodos a depender do objetivo e da idade dos participantes Em Processamento de Linguagem em Adultos: leitura automonitorada, testes de decisão lexical e de priming, e rastreamento ocular da leitura.

Soletras: Você poderia fazer uma estimativa do total de pesquisas de mestrado e doutorado que foram conduzidas no Lab?

O LAPROS foi fundado recentemente. Logo, as pesquisas de mestrado e de doutorado realizadas no laboratório ainda são as dos alunos da Professora Ruth Lopes, que presenciaram a mudança do SEAL para a nova sala do LAPROS. Acredito que temos quatro pesquisas de mestrado e doutorado experimentais em andamento no laboratório, além de três pesquisas candidatas ao mestrado e ao doutorado no próximo concurso da UNICAMP, sob minha orientação.

Soletras: O Lab integra alguma rede de cooperação? Poderia citar outros Labs parceiros?

Hoje trabalhamos em projetos conjuntos com o ACESIN e o LAPEX, ambos na UFRJ.

Soletras: Além de trabalhos teóricos de interesse para a área da Psicolinguística, seu Lab desenvolve também pesquisas de interface com a área da Saúde elou da Educação? Se sim, quais?

Não, no momento.

Soletras: Deixe uma palavra de seu Lab para os leitores alunos de graduação interessados em ingressar na área da psicolinguistica experimental.

Embora o LAPROS tenha somente um ano de vida, acredito que ele já é um laboratório completo. O laboratório é completo no sentido de materiais, contando com espaço, equipamentos e brinquedos para pesquisas em aquisição, computadores e softwares para experimentação além de um Eye-Tracker Gaze Point. Mas especialmente, o LAPROS é completo por atuar em três frentes importantes: Aquisição de Linguagem, Processamento em Adultos e Processamento de Linguagem Natural. Digamos que um aluno se interesse em uma 


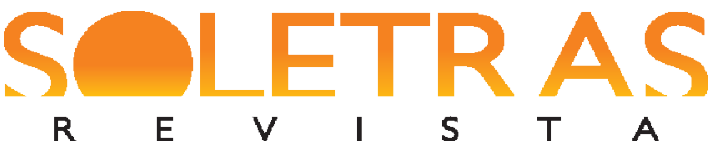

pesquisa sobre processamento de frases. A especialidade dos outros dois coordenadores pode abrir novos horizontes para sua pesquisa, podendo realizar testes com crianças ou pensar em modelos computacionais sobre o mesmo fenômeno.

Entrevista realizada em 10 de junho de 2017. 